Paper \# 04ICES-275

\title{
Water for Two Worlds:
}

\section{Designing Terrestrial Applications for Exploration-class Sanitation Systems}

\author{
Constance Adams, Architect, synthesis int'I USA \\ Ingvar Andersson, UNDP Water Development Programme \\ John Feighery, NASA-JSC (EG)
}

\section{ABSTRACT}

At the United Nations Millennium Summit in September of 2000 , the world leaders agreed on an ambitious agenda for reducing poverty and improving lives: the Millennium Development Goals (MDGs)', a list of issues they consider highly pernicious, threatening to human welfare and, thereby, to global security and prosperity. Among the eight goals are included fundamental human needs such as the eradication of extreme poverty and hunger, the promotion of gender equality, the reduction of child mortality and improvement of maternal health, and ensuring the sustainability of our shared environment. In order to help focus the efforts to meet these goals, the United Nations (UN) has established a set of eighteen concrete targets, each with an associated schedule. Among these is Target 10: "By 2015, reduce by half the proportion of people without access to safe drinking water." ${ }^{2} \mathrm{~A}$ closely related target of equal dignity was agreed at the World Summit on Sustainable Development (Johannesburg, September 2002): "By 2015, reduce by half the proportion of people without access to basic sanitation"3.

One of the greatest successes in the development of Exploration-class technologies for closed-loop, sustainable support of long-duration human space missions has been the work both ESA and NASA have done in bioregenerative water reclamation (WRS), and secondarily, in solid-waste management. Solidwaste and WRS systems tend to be combined in the commercial world into the field of sanitation, although as we will see, the most essential principles of sustainable terrestrial sanitation actually insist upon the separation of solid and liquid excreta. Seeing the potential synergy between the space program ALS technologies developed for Mars and the urgent needs of hundreds of millions of people for secure access to clean water here on Earth, we set out to organize the adaptation of these technologies to help the United Nations Development Programme (UNDP) meet Target 10. In this paper, we will summarize the issues and results of the first "Water for Two Worlds" summit held in January of this year, describe the status of the sustainable sanitation systems that are on the table for adaptation to widespread terrestrial use, and present fundamental strategies for forward work. 


\section{INTRODUCTION}

Although the suggestion that the experience base being developed in the human spaceflight program may be helpful to the UN's goals of improving global human welfare may seem to be a contradiction in terms, a long-term view of the very concept of globalism suggests the opposite. In many ways, the modern environmental movement was in part a response to seeing the first pictures of Earth as a planet during the Apollo missions of the late 60s. In what has become known as the overview effect, many astronauts have seen their lives and perspectives radically changed by the sight of an earth with no borders, a single global ocean, and one atmosphere. In this composite photo taken by earth orbiting satellites, it is somewhat easier to see the differences that exist on our planet. From space, the Earth is as a single organism comprised of multiple, complex elements engaged in constant interaction. ${ }^{4}$

Since the early 1960 s the idea has taken hold of our Earth as one planet, without national borders, influenced by regional geology and microclimates and fundamentally interdependent. The planetary view has radicalized most philosophies of boundary and compartmentalization, and shown us the extent to which the nature of Earth's systems and inhabitant species—our own included—is integrated, cyclical and codependent. More than three-fourths of the science payloads Columbia carried on her last mission were dedicated to the study of our planet's organic and inorganic structures, and the SeaWIFS and AQUA payloads are beginning to return some very exciting data on the interdependency of Earth's atmospheric and oceanic systems. It is not an accident that, since the 60 s, we have identified the effects of chlorofluorocarbons on the ozone formation of the upper atmosphere, resulting in a global ban that has just begun to show the first signs of gradual repair ${ }^{5}$. Such a thing could never have been detected before spaceflight, which produced both the iconic images that drove the philosophy of globalization, and also the communications technology that made it possible ${ }^{6}$.

\section{THE MOTHERSHIP IDEA}

This revelation has affected not only science and philosophy but politics and economics as well. Today's business methodologies, tools and economic models would have been unimaginable before the advent of satellites for weather, commerce, communication and analysis, all of which are products of our presence in space and our self-awareness as planetary citizens and brokers. The Millennium Development Goals themselves are dependent on an understanding of regional economic and cultural factors that are driven by geology - climate, resources and ecosystem -- and of the need to respond in a manner that addresses problems in context rather than separately. Separate solutions, like patches in a network of lines, are prone to ricochet effects in the larger system. These "unintended consequences" may arguably account for a high percentage of the environmental, economic and social degradation with which we must contend today. 
Building and flying human-rated spacecraft is a challenge of enormous technical complexity, and this undertaking has led us to understand our own planet in terms of its systems and interfaces. In developing vehicles and payloads to help us search for life on other worlds, we are coming to an ever greater understanding of the degree to which the Earth's chemical and physical composition, position and movement offer a uniquely tuned incubator for life as we know it. Because the planetary buffer is large, its integrated systems have managed to absorb a certain amount of insult; but as we are learning, even a minute change in the interactions of water, temperature and chemistry could have a devastating effect on Earth's ability to support life at the current level of biodiversity. ${ }^{7}$ More pointedly, we are now applying many of the models developed for aerospace and advanced manufacturing, like thermal and fluid analysis and integrated systems modeling, to our planet -- and discovering that the paradigm we have been striving towards was right here, all along.

This is the essence of the Mothership idea: that the Earth is our collective home, our original spaceship, and as such represents the ideal archetype for any and all vehicles or facilities intended to support human and terrestrial life. On the planet as well as off, the most robust and efficient designs for integrated structures of any kind are ones developed in a broad understanding of their context, their interactions and dependencies and their natural paradigms. Conversely, any structure or development that is buitt without regard for these things will almost certainly result in negative interactions and "unintended consequences" such as increased ground temperatures or wind, concentrations of unfriendly materials and diversion or pollution of the watershed -- much as the placement of an enormous payload in the center of a spacecraft's main air supply would eventually cause strain on all of the vehicle's systems as temperatures rise, fans overheat and gas exchange is constricted.

In order for a near-term human expedition to Mars or a return to the Moon to be viable, the NASA roadmap has identified a number of systems or technologies that must be developed. Because these must meet stringent requirements for reliability, low total system mass and minimal maintenance within the closed-loop context of a zero-contamination planetary science scenario, the development of sustainable, simple systems that closely resemble Earth's natural waste and water cycles is strongly indicated. Nonrecyclable consumables must be avoided as much as possible and power consumption kept to a minimum in a real planetary setting, two requirements that require a greater level of maturity than the Advanced Life Support [ALS] technologies already tested in conjunction with the Lunar-Mars Life Support Test Projects of the mid-1990s ${ }^{8}$; nevertheless, the success so far achieved in bioregenerative Water Reclamation Systems [WRS] both by $N S_{S}{ }^{9}$ and by the European Space Agency (ESA)'s MELISSA loop tests suggest that the ecological, biomimetic model on which they are designed is a strong approach for supporting long-term human well-being on Mars ${ }^{10}$. 


\section{WHAT IS TO BE DONE?}

For at least half of the human households on Earth, a solution to these same problems has also remained elusive. Throughout the developing world, not only the poorest communities are hard-hit by the lack of clean water and safe sanitation. Middle-class and agricultural households located in exurban areas downstream of major cities often suffer from a particularly noxious water supply thanks to the massive Western-style "flush and forget" sewer systems that were built in many developing countries by wellmeaning donor assistance programs in the mid to late twentieth century. This practice still continues at a larger and larger scale. These systems enable decent sanitation for some within the city, but do so simply by collecting wastes and contaminants and dumping these wastes into the nearby watershed. It is estimated that somewhere between six and eight thousand children die every day on our planet simply because their drinking water is not safe ${ }^{11}$, while an additional twenty-five thousand perish daily thanks to hunger, violence and other preventable health issues. Clearly, the human interface with the water system is badly broken.

Designs for systems to support long duration human spaceflight have a number of special requirements. Systems for water, sanitation and food production must sustain human life without depending on external power/water/sewage grids, and at the same time offer ways of recycling waste products into useful resources. Each habitable environment must maintain certain standards to guarantee the safety of the crew from contaminants; this monitoring function must be very low-maintenance and require as few consumables or replacement parts as possible. Monitoring systems for a Mars expedition must be rugged, compact, and field-deployable, and must provide a simple user interface without complex procedures or specialized knowledge.

In other words, all systems should be designed at a minimum cost to the mission, requiring little or no crew time to run and maintain in an environment where resupply flights are not an option should something wear out or break down. These criteria are also highly relevant to technologies supporting the Millennium Development Goals. Sustainable systems help promote ecological balance. Small, simple technologies can circumvent the machinery of bureaucracy and investment that all too often stands between foreign development cooperation programs and those they are trying to help, while lowmaintenance systems that run without expensive, exotic parts will work equally well for unskilled operators as for more sophisticated users.

In response to the recognition of this synergy, a coalition of experts in space architecture and technology and water/sanitation experts for developing countries called a meeting of colleagues from both sides to put issues and solutions on the table and to investigate opportunities for collaboration. 


\section{THE COLLABORATION}

The first "Water for Two Worlds" symposium was convened in New York City on the first anniversary of the launch of STS-107, in January of 2004. Hosted by the UNDP's Water Governance Programme and Columbia University's Earth Institute, the summit profited from the enthusiastic attendance and participation of representatives of ESA's Life Sciences directorate, NASA-JSC's Advanced Life Support group, the International Water Association (IWA) and some leading experts in innovation, patenting and the transfer or adaptation of technologies between North and South. All participants were requested to make a presentation on the first day of the summit; in the first period, the problem of water was presented in some detail, along with ongoing field efforts to address water supply and sanitation issues. Existing technologies and methods with the potential for addressing the problem were the topic of the second session. The third session of Day One was an effort by the group to summarize the lessons learned from the first two sessions, to establish achievable goals for the collaboration, and to identify specific areas of synergy that suggested a course of action. On Day Two the active participants for the second phase met $s$ to further refine the plan for forward work.

\section{TRICKLE-DOWN ECONOMICS: INTELLECTUAL PROPERTY, TECHNOLOGY AND POLLUTION}

When he introduced the Millennium Development Goals for improving the basic conditions of life around the world UN Secretary General Kofi Annan said, "First is water and sanitation." How can we maintain the quality and quantity of existing water resources for the purpose of poverty eradication and sustainable development? This is a staggering challenge and one that is fundamental to our collective well-being. Not only essential to health and life, the availability of clean water is critical for economic development, food security, energy production, productivity, environmental protection and economic injections from tourism and investment. ${ }^{12}$

The factors that drive the water problem are ones of governance, technology and finance. Governancerelated factors, such as the challenge of articulating these issues across the institutions, policies and structures of authority, impose the need to find alternate channels of delivery for new and sustainable sanitation technologies. While private sector initiatives might be brought in to the game, their effectiveness will be limited unless there is either a clear financial incentive or other structures to encourage them. In either case, the traditional sewage systems that require the construction of massive infrastructure are costly, aggressive undertakings that are unlikely to attract investment today. Multidimensional innovation-lechnical, institutional and financial-is one approach that may be used to circumvent the usual constraints to action ${ }^{13}$. 


\section{Intellectual Property}

Whether by outright invention or by adaptation of existing technologies, technical innovation offers one avenue for subversion of the roadblocks to universal water access. Although a review of existing patents clearly indicates that new water related innovations have a strong bias towards the needs of the industrialized North - with fully $50 \%$ of all water patents involving methods for desalinization of ocean water - a number of previous innovations may apply to today's specific needs in water and sanitation. Expiring patents for innovations in water purification, sewage treatment and other water / sanitation related issues may provide the needed solutions while minimizing the costs of research and development ${ }^{14}$.

\section{Technologv and Pollution}

The technologies that we in the North have been accustomed to using for sanitation are now recognized to be highly destructive to the wider ecosystem. Water-borne sanitation systems are "abusive to human well-being, unaffordable and environmentally unsustainable." One of the least visible consequences of many of the traditional development assistance programs led by Northern nations (many of them former colonial powers) in the 1960 s is the unfortunate proliferation of centralized urban sewage systems. This method, which uses massive civil engineering to collect excreta and channel it into large bodies of water, has earned the nickname "Flush and Forget" sanitation because all too often the waste water is not treated before it is dumped into water bodies, or "treated" just enough to dilute the city-dwellers' toxins and pathogens and deliver them to the inhabitants of the coastal and rural areas downstream who have no other water source on which to rely for drinking and hygiene.

Trickle-down pollution of this kind is one of the major areas of conflict between rural and urban areas. Many argue that it results from a failure to recognize certain fundamental principles, or at least an inability to see the connection between these ideas and the real problems that plague farmers and city-dwellers alike. According to the UNDP's Water Governance Programme, the classic urban sanitation system is essentially a nineteenth-century technology that is fundamentally flawed in that it ignores the basic principles of water:

1. Excreta are a valuable resource. In nature, there is no such thing as waste.

2. Water is precious; it is an essential ingredient of life. It is neither a sink nor a medium for filth. $^{15}$

\section{SPACE, WATER AND ARCHITECTURE}

These principles have tremendous implications for urban design and architecture as well as civil engineering, in the so-called 'developed' countries as well as in the developing world. If human excreta are to be treated as a resource, then systems for separating urine from fecal matter must be developed 
which are safe, clean and low impact in terms of user interface. Separating water from solid waste includes kitchen waste. In North America it is still common practice to inject a large percentage of plate waste and kitchen waste into the sewage cycle through use of sink-mounted grinders, even though this practice places so much strain on the water treatment system that it has been outlawed in Japan and much of Europe. Treatment of kitchen waste in a densely populated area implies organized composting systems, and suggests design strategies that include the integration of gardens with other structures such as roofs, parking lots and a variety of public spaces organized at a block or neighborhood level. Urban agriculture in turn bolsters nutritional status among the gardening population, and has the potential for invigorating the urban economy, if traditional marketplace areas can be recreated or revived to accommodate the sale of vegetables and other local foodstuffs ${ }^{16}$.

If water is to be treated with respect, then the delivery and recovery of potable water must be envisioned as an independent system based on principles of integrated water resources management. This idea also has design implications; for instance, a building conceived to collect and store rainwater, and to reuse greywater for hygiene and maintenance of the lobby's plantings while serving its program would have different structures and a different concept for systems integration than a traditional office building or apartment block.

\section{Equilibrium}

Separating the streams of the human ecological cycle begins to have another interesting effect on the urban environment: it re-forges the city's metabolic and economic connections to the surrounding countryside. Nightsoil, or the stored concentrations of human fecal matter that accumulate in a separation system, must be contained for several months before it can be safely handled and removed; but if it is composted under controlled forms during that time, the result is a very rich, inoffensive humus that could be put to use in farms at a savings to local farmers of tens of thousands of dollars per annum that are either spent on fertilizer or lost in reduced production due to the poverty of the soil ${ }^{17}$. Most of the nitrogen, phosphorus and potassium needed to replenish the soil is however in the urine which is safe to apply to fields without any storage period. Use of organic fertilizer also eventually lightens the chemical burden on the watershed; and little by little, the cycle regains equilibrium.

Equilibrium is the ideal goal of any spacecraft system design; and in learning to integrate the tremendous technical challenges of designing what is essentially an unsupported, hermetic human ecosystem, space architects are developing many of the skills that will be necessary to tackle the integration of sustainable utilities and sanitation to Earth's cities, communities and households. Some design principles suggest themselves for guidance when adapting a new technology to an existing system (or the other way around). 
First, the simplest design is always the most efficient ${ }^{18}$, assuming that the architects have already taken into account all the issues placed on the system by its inputs, outputs, interfaces and context.

Second is the principle of analogous or "synthetic" design: rather than setting out to reinvent the wheel, keep in mind that most functions that must be served by design have an analog in nature, as well as a solution.

Synthesis architecture

Following the concepts of simplicity and synthesis, the approach that we selected for beginning our assault on the water problem was to focus on decentralized delivery of portable, sustainable technologies. Driven in part by the availability of Advanced Life Support systems designed to support a Mars DRM-sized crew, this "plug and play" approach is not so much aimed at subversion of dominance paradigms as it is geared to speed and ease of delivery.

Small systems can be developed, tested, prototyped and delivered to an initial user group for field-testing at a minimum of cost and effort. Furthermore, if the systems hardware can be designed to reuse common items or to be readily manufactured locally, products can be delivered that are more likely to be both culturally acceptable and stimulating to the regional economy. These strategies increase the chance of success by making the user an active stakeholder in the process, and thereby raising the likelihood of adoption. The design strategy at which the Water for Two Worlds participants arrived for their first phase of action is to pursue development of small, simple, robust systems that aim at enabling the achievement (on a user-by-user basis) of household water autonomy. In preparing requirements for technologies to meet this goal, an immediate analogy is drawn to the Lunar-Mars Life Support Test Project (LMLSTP) Phase III test, and to the planned integration of multiple sustainable systems with human subjects in the Advanced Integration Matrix (AIM) facility at NASA's Johnson Space Center. These projects are analogous to the requirements of worldwide household autonomy precisely because they are themselves autonomous habitats supporting a group of 4 to 6 people, equivalent to a small household.

At the higher level of systems integration, the analogy may be drawn between the city-dweller's relationship to the urban water and sewage system and the relationship of the new system's user population to the Earth. We raise the level of the loop closure to the planetary system, since we understand this to be the pattern of origin. Our household systems are plug-and-play peripherals that concentrate certain aspects of the water and nutrient loops already present around us. Our technologies are designed to tap in to the utilities that are already hard-mounted: potable water in, hygiene water out; greywater in, nutrient loop out; food in, solid waste out; nightsoil in, fertilizer out; and so on. Consider the cost savings of this approach. In viewing the environment as a mothership and designing our systems to interact to its specifications and requirements-just as we must do when designing hardware or software 
for any spacecraft-we are able to skip huge, costly investments and avoid rigid structures. What makes this proposed design innovative rather than derivative is its adaptation of rigorous, closed-loop technologies in recognition of the Earth's limitations, and the resulting need to take individual responsibility for environmental pollution and sustainability.

\section{DEVELOPING STRATEGIES}

There are three principal issues that those designing any sanitation system will have to contend with. First among these is the problem of pathogens: how to detect their presence, how to isolate the user population from them, and how to remove them from the excreta rapidly and in a nonpolluting manner. Contamination detection kits can be extremely costly, difficult to obtain and challenging to use. Coming up with simple, inexpensive method for water monitoring will be critical to the effectiveness of autonomous water systems, and reducing the waiting period before fecal matter can be handled would contribute enormously to the proper and safe use of separation-and-containment sanitation. The water source is another issue, in that its quality, proximity and abundance can significantly alter the nature of the systems needed to ensure household water quality from location to location.

Last but by no means least of these issues is that of cultural acceptance: water and sanitation are inherently bound up with bodily functions that lie at the heart of many cultural taboos since they involve ideas of purity, gender, sexuality, life and death. No system that fails to take these taboos into account will meet with success. Regardless of its efficiency or elegance, if a technology does not meet with user acceptance it is worthless.

\section{Eco-San}

Water and sanitation policy experts presented a number of "home grown" strategies for improved sanitation that have developed and been adopted in disparate, relatively limited user populations and have met with a comparatively good rate of success. These range from the relatively simple Arbor-Loo, which has had good results in Mozambique, to the fairly sophisticated systems developed for use in advanced housing developments in Germany and Sweden. Various NGOs including SIDA and WaterAid are sponsoring pilot projects in ecological sanitation-or EcoSan - in rural, urban and peri-urban areas in South America, Africa, Mexico, China and India. All of these projects are structured to involve the community and their values in the adoption of technologies that are appropriate to their needs.

The EcoSan movement has tied innovative sustainability to scientific research in order to find solutions to a series of interrelated global problems. Major problems identified are related to common methods of management or mismanagement of land, water and sanitation; to wit:

- Pollution of aquifers, rivers, lakes and the seas, dying coral reefs

- Inefficient water usage through flush-sanitation (requires massive flows to function) 
- Dramatic loss of soil fertility around the world, dramatically underestimated

- The human nutrients cycle is broken, mixing of faeces with the water cycle without treatment contributes largely to the 5 million people dying from waterborne diseases

\section{Arbor-Loo}

Among the examples of eco-san technologies that have successfully contributed to better sanitation in rural settings, first was the arbor-loo, a movable outhouse that is designed to permit the users to pick up and shift to the side when the original pit is full. Little more than a movable pit latrine, the arbor-loo can be set up more or less anywhere with a little extra space, to provide users with a private and sanitary outhouse. Once the pit is full, the Arbor-loo structure is lifted up and moved several meters away to sit over a new pit. A tree is then planted in the old pit, and grows rapidly to recycle the nutrients that have been left in the soil.

Advantages of this system include its portability and the direct and immediate recycling of the excreta in the form of fertilizer for new banana trees. However, concerns about keeping untreated waste separate from the groundwater and from food-producing plants until it has been through at least one prior cycle of filtration make the Arbor-Loo a less than satisfactory solution for the long term. Also, its applications are limited to rural areas where land is available for planting; it is not likely that this system would work very well for long in more densely populated, space-restricted locales.

\section{The Sorting toilet}

It appears the most central common technology in an effective, sustainable system for human sanitation is the separation of liquid and solid wastes; or in other words, a toilet-type fixture that is designed to collect the urine separately and to siphon it away from the solid waste. As long as solid waste remains dry, the unpleasant odors associated with it rapidly dissipate and any pathogens that have been excreted have little opportunity to spread. This principle suggests the design of new hardware that can effect sanitation without sewers. Along the same line, autonomous, household-sized systems can be envisioned that collect and deliver water without pipes, and are able to manage local resources on a userby-user basis.

One hardware item that can be used for ecological sanitation systems is the Gustavsberg sorting-toilet that separates urine from fecal matter and runs the liquid waste into a garden; although the caveat must again be issued that it is best not to run urine directly into vegetable crops ${ }^{19}$. This technology has received a good deal of attention in Europe, although not exclusively. Major sanitation industry players are looking into the profitability of developing some eco-san-compatible units for private use, including Vivendi and Villeroy \& Boch; but a small fiberglass shop in central Mexico has been enlisted to produce a 
similar product that has been successfully field tested as well. In the Swedish new town of ???, a separation system for treatment of liquid and solid waste has been built, and these toilets put to use; likewise in the German town of Luebeck-Flintenbreite, where a vacuum system has been installed to draw the solid waste to a central location where it is ground into homogeneous material.

\section{Decentralized waste treatment}

The separation of waste streams requires that systems be in place for treatment of the urine and fecal matter, and for the runoff of hygiene processes, known as greywater, as well. While it is certainly possible to conceive of a central network for this type of treatment, this idea is not very practical due to the cost and complexity of moving all the separate waste streams to central locations. Once again, we are looking at a strategy that strongly implies the decentralization of waste treatment, either at the household level where density is low (like the Earthship, which we will discuss shortly), or at a neighborhood level where density is high. Various approaches can be taken to treating the different streams: two of the most common are the reuse of greywater for hygiene and gardening, and the use of special gardens for treatment of yellow water.

Other strategies include the construction of wetlands for reprocessing greywater, as well as more intensive "digesters" for blackwater as in the Projekt Freiburg-Vauban, also in Germany. Another major problem is the new and increasingly significant presence of pharmaceutical residues in the water supply. Human waste, however carefully filtered, continuously adds organic, pharmaceutical compounds such as antibiotics and hormones (like estrogen) into watersheds the world over; and because of their structure, these compounds are all but impossible to extract.

\section{The Diet of Worms}

A pilot project for addressing this issue in solid waste is underway in Lambertsmuehle, where a two-year composting tank is being scoured through the intervention of large numbers of worms. Tirelessly aerating the soil, worm activity has long been valued by gardeners; but their constant feeding has the added value of consuming and processing organic compounds and pathogens. According to the International Water Authority (IWA), every 1 gram of fecal matter contains some 10 million viruses and 1 million bacteria, and can contain 1000 parasite cysts or 100 parasite eggs. For these same reasons, it is imperative that the products resident in pit latrines be kept separate from groundwater.

However, the Lambertsmuehle worms have also demonstrated an ability to expedite the neutralization of solid waste. Since worms consume these microorganisms, their presence in systems for the safe, sustainable conversion of human waste is invaluable; current studies suggest that active worm action in fecal composting can reduce the quarantine period from six to only two months, and perhaps eventually 
even less. Research into the application of this process to Exploration-class solid waste management might prove extremely valuable for long-duration space missions.

One final characteristic of sustainable sanitation systems is their independence from central networks, which makes them remarkably cost-efficient for the end user.

Notably absent from the Eco-San strategies to date is any kind of system for ensuring the potability or cleanliness of the household water supply; while most of the sanitation systems do separate urine from fecal matter at the point of collection, the urine is generally either dumped elsewhere or used to help fertilize crops. This "yellow water" is generally not reused or cleaned, and the reuse of household greywater for gardening is not uncommon; but whatever focus currently exists on water treatment is primarily at the removal point and not at the point of entry to the household.

\section{Earthships}

The Earthship movement, which has begun to take hold in the Western United States over the past decade and a half, is an interesting example of adaptation of architecture to invite and support simple, sustainable systems to run a fully modern American home. These homes are of a passive solar design, typically built of thick masonry walls made of used tires packed with dirt, or of used aluminum cans stacked and stuccoed over with concrete. The masonry walls provide considerable thermal mass on the north, east and west walls of the house and permit the construction of a glass south wall to light and warm the home and support an interior greenhouse garden. While the water-collecting shape of the roof might not be of much use on Mars -the roofs usually scoop rainwater into a sterile collection tank for storage - much of the systems-sensitive design of an Earthship offers an excellent paradigm for in-situ habitat construction in remote locations. Hygiene water is rerouted internally to the kitchen garden, and solid waste is composted on site; some advanced Earthships are even working toward water treatment through their garden loop.

For all its virtues as a paradigm, the Earthship itself is nonetheless a structure whose current form still presupposes a context of wealth. The environment providing all the utility inputs is clean, dry, temperate, sunny and lightly populated; receiving acid rain at a latitude that is severely constrained for light, for instance, or the need to dispel heat and humidity in a tropical environment, will add requirements to future Earthships that have not yet been encountered. Most challenging to adapt to common use in Southern economies on Earth is the fact of inherent value: the Earthship requires tremendous investments of labor and know-how to build, and is not transportable. Thus, only the user who is also a landowner is likely to find such a significant investment worthwhile. It is not a useful archetype in places characterized by situational uncertainty like areas suffering from regular shortages of water or crops, from warfare or sporadic conflict, or in urban areas, where homeownership is restricted to a very small sector of the 
population. The Earthship may prove to be a more valuable technology in the parts of the world that are wealthier in resources and typically more abusive to the environment.

\section{Ethnocentricity of value}

Technologies are generally considered appropriate or inappropriate to an application when their capacity fits the functional requirements. This is true of value as well; and value, it is well established, is culturally relative in almost every way. Innovations have also been found to have radically different value in different cultural and economic contexts; in this way, they can be considered ethnocentric. One example is given of value-ethnocentricity with regard to an invention that uses air bladders in the soles of the wearer's shoes to generate pressure sufficient to release water (stored in a tank worn like a backpack) at considerable force from a hand-held nozzle. In India, where this ingenious device was cobbled together by a subsistence farmer in need of a better way to irrigate and fertilize his crops, it cannot be produced or sold at very high cost and has value as a tool for enhancing the user's fundamental subsistence. Once patented in the USA, however, this technology was sold for a great deal of money to a toy manufacturer and is expected to reap colossal profits from its application in a newfangled water gun-cum-exercise shoe, in which manifestation its value is purely one of entertainment and probably short-lived. ${ }^{20}$

It is especially important for those undertaking the adaptation of high-performance technologies to subsistence uses to keep this lesson in mind. What is value? In the equation above, cost-value and intrinsic value of the bladder-pump add up to roughly equivalent total value in both applications, but while the cost-value is higher in the Northern economy, in the Southern economy it is of far greater intrinsic value. A simple, hand-made kitchen tool produced for home use by an African woman may be treasured as an example of primitivism and artisanal skill in Paris. And costly "space age" technologies for the first human mission to Mars, that have little more than cachet for those of us with instant access to ubiquitous sources of clean water, may find their highest intrinsic worth as the source of life and health to two billion people on Earth.

\section{WATER FOR MARS}

Long-duration sustainable sanitation systems can go one of two ways: either recycle organic waste for its valuable nutrients or collect, stabilize and store the waste for future use of an undefined nature. The former solution requires that multiple cycles and systems be nested, which has short-term drawbacks in terms of cost and complexity but long-term value as a more stable system. One alternative to growing traditional food crops is algae farming. Algae are an excellent if unconventional food source, and offer greater stability in the $\mathrm{O} 2 / \mathrm{CO} 2$ cycle. 


\section{MELISSA, Concordia and the ESA offerings}

ESA has several facilities dedicated to ongoing research on life support systems that can sustain an extended human presence in space or on other planets. These include the ARES Air Revitalization System as well as various technologies for treatment of greywater, yellow water [urine only without exposure to fecal matter] and blackwater.

In the area of bioregenerative water revitalization, the MELISSA project encompasses several research efforts into different if complimentary approaches. Compartment I of the MELISSA loop uses thermophilic anaerobic bacteria to break down contaminants in the wastewater; Compartment II uses specialized photoheterotropic bacteria, and Compartment IV uses photoautotropic bacteria.

These loops represent the bioregenerative component of a hybrid physicochemical/bioregenerative sanitation system that has been installed at the European Concordia station in Antarctica. ESA's charter compels the Agency to identify synergies between space research goals, findings and technologies that have resulted from space research, and the needs of the citizenry of Europe and the Earth. As a result, ESA already has experience in the transfer or adaptation of their technologies. The Concordia system will be fully operational in July 2005 , using anaerobic degradation for treatment of blackwater; hybrid systems to treat greywater for summer teams of up to seventy people will be operational by July 2004 .

\section{NASA and the problem of water monitoring}

The International Space Station uses both ground-supplied stored water and processed condensate recovered from air conditioning systems to meet the drinking and hygiene water needs of the current crew of 2 or 3 persons. With very limited opportunity for sample returns (twice per year) and no on-orbit laboratory for water quality analysis, ensuring that the crew has a dependable and safe water supply that meets US and Russian requirements for potability is a significant challenge. The current approach is to monitor the water using lightweight, disposable test kits that are specially designed to work in zero gravity. As such, NASA has and will continue to invest in research leading to simple, quick, and reliable methods to measure various aspects of water quality including pathogen load, organic and inorganic contaminants, and general indicators such as $\mathrm{pH}$ and conductivity.

Many of the goals of water monitoring in spacecraft coincide with desirable attributes for monitoring of sustainable water and sanitation systems. These include:

1. Rugged. No refrigeration capability is available on the International Space Station; therefore, media used for culturing bacteria or chemical indicators must often be stored at temperatures and conditions outside of those recommended by manufacturers and NASA has built up data over the years to validate the analytical performance of systems exposed to harsh environments. A similar 
problem is encountered in deploying water monitoring technology in remote areas or urban regions without access to electricity.

2. Compact. Space systems are subject to extreme limitations on volume and mass. All the components used in an analysis must be provided in one package that is easy to transport.

3. Field Deployable. Once a monitoring device is on the Space Station, it must be easy to set up and tear down to make room for other experiments and routine operations. Similarly, the most suitable operations concept for monitoring many independent rainwater collection and storage systems is a system that is not tied to a particular location, but can be transported to each location as necessary.

4. Simple. Since Space Station crewmembers must receive training in the operation and maintenance of hundreds of spacecraft systems, only a few hours can be allotted to water monitoring. On earth, very few individuals have the education and training to conduct laboratorylevel water analysis. To move away from traditional central water supply and sewage treatment systems, monitoring must also move out of the central laboratory and into the hands of less experienced operators in the field.

Since water monitoring for spacecraft and ecological sanitation systems share many of the same goals, opportunities exist for collaborating through knowledge sharing and technology development. The first step would be to integrate NASA water monitoring technology and expertise into the Household Water Autonomy Concept presented in this paper.

\section{WATER FOR EARTH}

The third period of the symposium's Day One involved the review of our common findings and establishment of common conclusions.

\section{MAIN CONCLUSIONS}

1. We need to preserve and protect Earth's resources, fresh water and soil fertility for future generations. Today we have more than 6 billion people living on the planet. Soon $50 \%$ of the population will be urbanized, living within $50 \mathrm{~km}$ of a coastal system. We are pushing natural resource limits, and worrying about pollution limiting our use of other resources. The problems we have today cannot be solved with the same kind of thinking that created them. Business as usual approaches to water and sanitation / waste management will fail to provide the poor with the services promised in the MDGs. A new approach is needed. 
2. The analogy between spaceflight technologies and sustainable Earth systems is relevant. Sustaining life in both space systems and earth ecosystems have the common goal of operating in a closed loop system with minimal external input.

3. Research and development on space technology have high relevance for terrestrial water and sanitation applications. A number of success stories on technology transfer from space to terrestrial use can be reported such as i) Biostyr - nitrification and de-nitrification process (ESA); ii) Concordia station -water recycling systems (ESA); iii) Biomass sensor - biological activity determination (ESA); iv) BIOMET - heavy metal management (ESA).

Furthermore, most experts working on space research are de facto terrestrial experts and have knowledge and skills to address very practical problems. Space architects have extensive knowledge of terrestrial models combined with a rare and emerging mindset of integrative, sustainable systems design as a fundamental aspect of the built environment.

4. The "ideal" technology on water and sanitation services for the poor to meet the MDGs should include the following characteristics:

- low on energy demand

- reliable and easy to maintain

- $\quad$ easy to operate, user friendly

- culturally acceptable and address men's and women's specific needs

- affordable to the consumers

- maximize health benefits, high safety and quality control

- minimize pollution, highest possible recycling level

5. Constraints in space application lead to highest requirements in terms of:

- low mass, low volume

- low energy

- highest efficiency

- higher control

- flexibility

6. Research on space technologies is highly relevant to address terrestrial needs such as:

- individual, portable and manual recycling systems (one household)

- village or neighborhood water recycling systems (grey, yellow and black water)

- heavy metals detection and removal

- sanitation (one household) 
- high protein complements production

- maximized reuse of organic waste

7. The space agencies have competencies highly relevant to support terrestrial sustainable development approaches including "high closure of the loop" and "from water to food processes"

8. Development of new technologies should be balanced against the identification, adaptation and promotion of existing innovations to meet today's specific needs in water and sanitation for the poor.

9. Financial constraints are an important consideration when transferring technologies to developing countries. There are specific needs to consider the financial sustainability of implementing and maintaining the technology. In addition to a financial feasibility assessment, an overall assessment of stakeholder identity and community needs must be undertaken, keeping in mind issues of gender roles, local economy and political dynamics.

\section{PHASE ONE: ESTABLISHING "HOUSEHOLD WATER AUTONOMY"}

On the second day of the summit, a plan of action was roughed out for near and long-term phasing of efforts to adapt Exploration-class technologies for the use of Earth's population.

The first phase of this collaboration will focus on a low-end application of ALS water systems in largely rural and then urban slum settings; one of the principal challenges in the initial phase is responding to the need for these systems to be easy to lay out and build in a small home at little or no cost to the user. In the former, the project's goal is to develop a sustainable, low-tech system that improves general sanitation and reduces child mortality; this low-cost design will offer knowledge back to the space program in the form of simplified, robust versions of the ALS waste treatment suite.

\section{The way forward}

Participants agreed to establish an informal network (the Water For Two Worlds Alliance, W42WA) to bring the Earth and space research communities together. The UNDP will initially be the focal point of this Alliance.

UNDP offered to identify 2-3 communities appropriate for testing the relevance of the space agencies' research abilities. The sites selected cover rural, peri-urban and urban settings as well as different physical, socio-economic and cultural environments. UNDP is now in the process of providing the researchers with information about these test cases so that system requirements can be established. Using its network of country offices and local NGO partners, UNDP will obtain the best possible 
information and lead the field testing of new technologies as they develop. The space agencies will contribute with feasibility studies and "in-situ" demonstrations.

In response to the recognized need to develop different technologies for different "grades" of pollution, a tentative "division of labor" emerged:

- IWA - black and yellow water

- ESA - grey and yellow

- NASA - test of potable water ${ }^{21}$

- Synthesis architects - design studies on appropriate urbanistic and design strategies for the target sites (rural and urban)

Relevant ESA technologies to be investigated or adapted include filtration technologies and biological processes. Preliminary conceptual studies commenced immediately, with initial results to be reported at the next Alliance meeting in August of 2004. The proposed collaboration with UNDP will include two types of activities carried out in parallel:

- Continuous exchange of information: "brainstorming"

- Study of specific cases

\section{Action plan}

- Identification of areas where space technologies could be used (UNDP)

- Requirements definition (UNDP):

- Concept studies (ESA)

- Feasibility studies (ESA): phase A

- Prototype development

- Laboratory tests

- Validation (according to UNDP requirements)

- In-situ evaluation (field prototypes): advantages and weaknesses

- Improvements

- Implementation of the concept (UNDP): with ESA support

\section{Water Architecture}

While there are many technical questions to address in streamlining bioregenerative systems for application in places where exotic technologies like disposable filters cannot be found, the architectural aspects of this program also offer many opportunities for innovation that may prove valuable to the design of sustainable homes the world over. There are a few precedents upon which we are building our formal approach, such as the Mexican and Swedish waste-separation structures and certain of the green techniques that have been applied to date in the Earthship movement. However, none of these is 
comprehensive in terms of suggesting either construction methods or design strategies for field implementation of bioregenerative systems for applications at any level of investment. New design strategies for common building types will begin to emerge as the application spreads, leading space architecture to adapt some new principles of water design.

Once plug-and-play system units for household water autonomy have been developed, the adaptation of simplified Exploration-class water technologies to their terrestrial field context will become the subject for design studies. Simplicity, adaptation and cultural acceptance clearly are preferable to high-tech, objectoriented solutions when the goal is rapid deployment, broad acceptance and long-term success; furthermore, the relationship of household potable technologies to village or neighborhood composting and treatment paradigms will require iteration. A series of patterns will need to be established for rural, exurban and urban settings based on population density, local custom and the availability of public space.

\section{SUMMARY}

In recent years, much of the technological capacity of the wealthiest Northern economies has been focused on the development of systems and technologies to support human exploration of the solar system. Some of the earliest successes in this area have been in sustainable systems for water recovery and sanitation that are especially well suited to the requirements of a household-sized crew on a mission to Mars. Meanwhile, one-third of the inhabitants of our water-rich Earth are living without clean water or access to sanitation, problems that threaten the health and economic well being of the poor and cause the death of thousands of children every day.

Previous attempts to balance the problem by providing massive sanitation infrastructure to selected urban centers around the world have compounded the total pollution issue by blocking normal watersheds and delivering concentrated urban pollutants to those who live downstream. Meanwhile, issues of governance, finance and institutional rivalry have prevented the delivery of many goods and services to those most in need all over the developing world. The best solution to the most immediate problemchild mortality - would have to be effectively independent of existing structures, simple, portable, effective and based on organic principles that do not generate problematic waste products and are low in the consumption of power and consumables.

These qualities are also required characteristics of the most advanced water recovery systems in the world: the Exploration-class technologies on which NASA and ESA researchers have been focusing over the past decade and a half. An ad-hoc group, the Water For Two Worlds Alliance has organized to exchange their expertise in needs and capabilities, and is now in the process of developing requirements for the adaptation of existing space WRS technologies to two or three test cases. Once prototyped, these 
technologies will be delivered and field-tested by various NGO organizations under the auspices of the UNDP, with an initial focus on the goals of household water autonomy and neighborhood (village) scale sanitation and treatment. It is hoped that these two fundamental design principles will prove valid and will pave the way to ever broader practice of synthesis architecture in the planning and design of structures, neighborhoods and cities.

\section{ACKNOWLEDGMENTS}

All the participants and organizers of the Water for Two Worlds Symposium have made significant contributions of their time and expertise to this groundbreaking effort. Many participants have donated personal time and funds to pursuing the goal of potable water for all:

Roberto Lenton, Millennium Project Task Force on Water and Sanitation

Upmanu Lall, Columbia University

Albert Wright, Millennium Project Task Force on Water and Sanitation

Constance Adams, Synthesis International Inc.

John Feighery, NASA

David Martin, M-CAM

Didier Schmitt, ESA

Christophe Lasseur, ESA

Aurelien Pisseloup, ESA

Rolf Otterpohl, IWA and The Technical University of Hamburg

Ingvar Andersson, UNDP

Lara Yacob, UNDP

If we succeed in saving even a few children's lives, we will have given them the whole world.

\section{REFERENCES}

\footnotetext{
For a complete list, please visit the UN website: http: / www undp.ord/mdg

${ }^{2}$ http://www.uninillenniumproject.org/htmidev goals.sintm

${ }^{3}$ htp:i iwww.un orglesaisustcievidocuments WSSD PO/_PD/English/POIChapter4 htm

${ }^{4}$ Adams, Constance (Aug, 2003). "Natural Unity: a Theory" essay for The Economist.

${ }^{5}$ NASA Press Release 03-253, July 29, 2003; nttp:lioea.larc.nasa.govinews rels/2003/

${ }^{6}$ Adams, Constance (2003). "HyperGlobal Communication: Developing the new Esperanto $400 \mathrm{~km}$. Above the Earth", in Form und Zeichen -- Globale Kommunikation, Proceedings of the Internationale Forum für Gestaltung Ulm. Sabine Süß, ed.; Birkhauser Verlag: Stuttgart. ISBN 3-7643-0446-4
} 
7 Ward, Peter D. and Donald Brownlee (2002), The Life and Death of Planet Earth: How the New Science of Astrobiology Charts the Ultimate Fate of the World. Henry Holt and Company, LLC, New York, NY. ISBN 0-8050$6781-7$ (hb.)

${ }^{8}$ Henninger, Donald (2000) Introduction to Advanced Life Support In Isolation: NASA Experiments in ClosedEnvironment Living, Lane, Sauer and Feeback eds. American Astronautical Society: Univelt, San Diego

${ }^{9}$ Smith, Frederick et al (1999) Water Recovery of Reverse Osmosis Brine and Pretreated Urine with an Air Evaporation Subsystem, in Proceedings of the $29^{\text {th }}$ International Conference on Environmental Systems; Society of Automotive Engineers, Warrenburg, PA

${ }^{10}$ Lasseur, Christophe (July, 2002). "Crew and Life Support" presentation at Alpbach Summer School; ESA.

${ }^{11}$ UN World Water Assessment Programme (2003). Water for People, Water for Life, The United nations World Water Development Report

12 MDG Task Force on Water and Sanitation (Dec., 2003). Interim summary report "Achieving the Millennium Development Goals for Water and Sanitation: What will it Take?" page 2.

${ }^{13}$ Lenton, Roberto (2004). "The Millennium Development Goals for Water and Sanitation" in UNDP report Water for Two Worlds: Can space research contribute to the achievement of the Millennium Development Goals on Earth? United Nations Development Program, New York, NY. Draft, not yet published at time of press.

${ }^{14}$ Martin, David E (2004). "Innovation Management - The Human Commerce Factor", in UNDP report Water for Two Worlds: Can space research contribute to the achievement of the Millennium Development Goals on Earth? United Nations Development Program, New York, NY. Draft, not yet published at time of press.

15 Ibid.

${ }^{16}$ Esrey, $S$ et. al. (2000). Closing the Loop. Ecological Sanitation for Food Security, UNDP and Sida ISBN:91-586$8935-4$

17 ibid.

${ }^{18}$ Adams, C and M. McCurdy (2000). Optimized Space Mission and Vehicle Design: Habitability as a Tier-One Criterion in Advanced Space Mission and Vehicle Design, Part 3, in Proceedings of the $30^{\text {th }}$ International Conference on Environmental Systems; Society of Automotive Engineers, Warrenburg, PA

${ }^{19}$ Otterpohl, Ralf (2004). "Reuse-oriented water and sanitation concepts, high-, medium- and low-tech options: Terrestrial initiatives on R\&D for water and sanitation reuse and recycling", in UNDP report Water for Two Worlds: Can space research contribute to the achievement of the Millennium Development Goals on Earth? United Nations Development Program, New York, NY. Draft, not yet published at time of press.

${ }^{20}$ Martin, (2004)

21 The US researchers' participation depends on NASA senior management approval.

\section{ADDITIONAL REFERENCES}

The Millennium Development Goals

UN Millennium Project

UNDP

UNDP Water Programme

$\mid \mathrm{RI}$ http://www. undp.org/mda

http://www.unmillenniumproject.ord'

http://www undp.org

http://www.undp.org/water

http//iri.columbia.edu 
IWA

IWA, Specialist Group on Ecological Sanitation NASA

NASA, Johnson Space Center, Advanced Life Support ESA, Advanced Life Support

MELISSA bibliography

Space Architecture synthesis international USA the mothership institute

M-CAM

Earthship movement http:i/www.iwahq.org.ukl

http:i/www.iwahq.org.uk

hitp://www nasa.gov

http://advlifesupport.jsc.nasa.aovi'

http://www.estec esa.nlecls/default html

http://www estec.esa.n//ecls/melissa/bibliographw.html

http://www.spacearchitect.org

http://wwn. synthesis-intl.com

hitp://www. mother-ship.org;

http://www.mothership.ce

hitp://wwo.m-cam.com

hitp://www. eanthship.org

LASSEUR Ch., VERSTRAETE W., RICHALET J. " Process and equipment for organic

waste treatment and applications of the process" French patent 9602131, ESA,

21/2/96.

Sawyer, Ron (2003), TepozEco Urban Ecosan Pilot Program Report, Sarar Transformación SC, Tepoztlan, Mexico.

\title{
ABBREVIATIONS AND ACRONYMS
}

\author{
ESA European Space Agency \\ NASA National Aeronautics and Space Administration \\ UNDP United Nations Development Programme \\ MDGs Millennium Development Goals \\ WRS Water Recovery System \\ W42WA Water for Two Worlds Alliance \\ LMLSTP Lunar-Mars Life Support Test Project \\ AIM Advanced Integration Matrix \\ MELISSA Micro-Ecological Life Support Alternative \\ NGO Non Governmental Organization \\ IWA International Water Authority \\ Sida, SIDA Styrelsen för Internationellt Utvecklingssamarbete [Swedish Int'I Development Ass'n] \\ EcoSan Ecological Sanitation
}

